\title{
Improving production planning through finite-capacity MRP
}

\author{
Tommaso Rossi ${ }^{\mathrm{a}}$, Rossella Pozzi ${ }^{\mathrm{a}}$, Margherita Pero ${ }^{\mathrm{b} *}$ and Roberto Cigolini ${ }^{\mathrm{b}}$ \\ ${ }^{a}$ School of Industrial Engineering, Carlo Cattaneo - LIUC University, Castellanza, Italy; ${ }^{b}$ Department of Management, Economics \\ and Industrial Engineering (DIG), Politecnico di Milano, Milano, Italy
}

(Received 5 October 2015; accepted 6 April 2016)

\begin{abstract}
Materials Requirement Planning (MRP) technique is widely employed by most manufacturing companies, even though field applications point out some weaknesses, including ignored production capacity constraints and fixed lead-times. These weaknesses often lead to infeasible production schedules, which trigger fluctuating workloads over time, significant adjustment effort and eventually unpredictably long lead times. This paper introduces a capacity-oriented MRP procedure that combines the traditional MRP procedure with an approach based on linear programming: in this way, requirement of lead times pre-determined a priori outside the MRP procedure is overcome. The new procedure is then applied to a real-life company and results highlight that feasible plans of orders are generated without requiring lead-times as input and without relevant computational burden.
\end{abstract}

Keywords: MRP; linear programming; capacity planning

\section{Introduction}

Orlicky's (1976) seminal work on Material Requirements Planning (MRP) has remained popular through decades: some years ago, almost $75 \%$ of manufacturing companies employed MRP as the main method for materials planning (Jonsson and Mattsson 2006). Even nowadays, MRP is an up-to-date tool, widely employed by manufacturing companies (Öztürk and Örnek 2012) due to its adaptability to dynamic demand fluctuations and to its ability to determine in advance what and how much to order to both internal and external suppliers. Indeed, MRP is more popular than reorder point-based inventory planning systems and mathematical programming approaches (Segerstedt 1996; Chen and Ji 2007).

However, when used in field applications, MRP shows some weak points: it ignores facilities capacity constraints and assumes fixed lead-times (Rossi and Pero 2011; Jodlbauer and Reitner 2012; Sun et al. 2012; Dolgui et al. 2013; Aouam and Uzsoy 2015). Either shortcoming above leads to infeasible production schedules, fluctuating workloads over time and significant users' effort to adjust the plans. In particular, the waiting time caused by the competition to chase bottleneck facilities causes unpredictably long lead times, eventually triggering the increase of planned lead-times, according to a common managerial practice. In the end, excessive work-in-process inventories and erratic lead times affect the production systems (Billington, Mcclain, and Thomas 1983).

MRP II and Closed Loop MRP evolved from the application of MRP in field (Wight 1995). In particular, MRP II includes a Rough-Cut Capacity Planning (RCCP) phase, which is based on fixed lead times and checks the plan compliance to capacity constraints. However, RCCP does not give assistance to managers in the process of adjusting day-by-day schedules (Rossi and Pero 2011). On the other hand, Closed Loop MRP tries to get automatically a feasible plan, by applying specific procedures. However, Closed Loop MRP is just a reactive procedure, and it does not change the structure of the MRP algorithm, which is still based on fixed lead times, and thus similar to MRP II.

Finally, some other finite-capacity MRP procedures early proposed in literature (Reiter 1966; Godin and Jones 1969; Goldratt 1980) proved to be computationally very complex in their seminal formulation, which led to a plethora of heuristics aimed at reducing the problem size and so the computational burden (e.g. Miltenburg 2001). However, most of these heuristic procedures still require pre-defined lead times (Rossi and Pero 2011).

This paper aims to define a capacity-oriented MRP procedure to help practitioners plan their production systems by also overcoming the requirement for lead times pre-determined a priori outside the MRP procedure. In particular, this paper addresses the relevant number of manufacturing companies still using MRP as their main tool for materials planning (Milne et al. 2012; Milne, Mahapatra, and Wang 2015).

\footnotetext{
*Corresponding author. Email: margherita.pero@polimi.it
} 
The paper is arranged as follows: Section 2 presents the literature review. Section 3 introduces the methodological pattern followed and presents the new finite-capacity MRP procedure. Sections 4 and 5 apply this procedure to a real case. Finally, Section 6 draws some concluding remarks and outlines future research paths.

\section{Literature review}

Despite the number of approaches proposed by researchers and practitioners, the field performance of MRP procedures that consider capacity constraints is unsatisfactory (Lee, Park, and Park 2009), which makes the development of MRP procedures still an open issue. In the last decades, several approaches have been introduced: they take advantage on various techniques (Rossi and Pero 2011), including algorithms, simulation and linear programming (LP).

\subsection{Approaches based on algorithms}

In the domain of algorithmic approaches, Agrawal, Minis, and Nagi (2000) developed the Lead Time Estimation and Scheduling Algorithm: it takes into account capacity constraints by firstly defining the lot sizes that minimise Work in Progress (WIP) of each product and then by estimating the most accurate lead-time of the previously identified lots. The lead-time above corresponds to a pre-defined product mix and to an estimated overload ratio of each resource.

Later, Horiguchi, Raghavan, Uzsoy, and Venkateswaran (2001) proposed an algorithm that estimates the start and finish date of each job scheduled on each critical resource: their algorithm considers the available time for all the feasible combinations of time bucket and critical resource, and it reduces the available time whenever a new production order is added to the schedule. This approach, due to the high aggregation level in modelling resources and relationships, might lead to orders overlapping on the same resource in the same time bucket (i.e. unfeasible plans).

More recently, Ioannou and Dimitriou (2012) presented two methods to incorporate the estimated lead times in typical MRP calculations. All incoming orders of their make-to-order manufacturing system, are given an estimated completion time by means of an iterative decomposition algorithm based on processing requirements of orders and on the current status of the manufacturing system. The decomposition algorithm operates anytime a new job enters the system, while the workload (due to the jobs already on the shop floor) is managed through 'first come first served' dispatching rule, which requires a number of time consuming operations.

Taal and Wortmann (1997) early introduced a seven-step algorithm that extends the MRP procedure: as under traditional MRP, lead times are given and capacity issues are managed by applying different techniques, such as alternative routing, lot splitting, safety stocks and backward shift of late orders. In a similar way, Jodlbauer and Reitner (2012) proposed to modify the traditional MRP procedures, on the one hand by considering dynamic lead times and, on the other one, by adding to the MRP run the planning of capacity at each level of the Bill of Materials (BOM). This is achieved by integrating different techniques for capacity adjustment, such as safety stocks or lot splitting. However, this approach does not make sure that the plan of orders is actually a capacity-feasible plan.

Later on, Kanet and Stößlein (2010) proposed the Capacitated-ERP method for one-stage production, single-level bill-of-material, single-resource without backorders. It takes into account the capacity of each resource and, if needed, it solves capacity infeasibilities, e.g. by adding production capacity before exploding the requirements of lower level components.

Along the path of integrating MRP procedure with forward and backward scheduling techniques, Pandey, Yenradee, and Archriyapruek (2000) developed the Finite Capacity MRP (FCMRP). This method is remarkable for the simplicity of the kernel algorithm, and because it takes into account WIP. Later, Wuttipornpun and Yenradee (2004) tested this approach in multi-product multi-level assembly operations with bottleneck stations, showing that FCMRP can reduce overtime, but it can increase earliness and/or tardiness. Therefore, Lee, Park, and Park (2009) proposed an approach based on the Longest Tail First rule to minimise the total lead-time of FCMRP, thus minimising the tardiness that might be caused by a rescheduling procedure. However, the no-common-parts assumption remains a relevant hurdle for this approach.

\subsection{Approaches based on LP}

LP is broadly exploited in the operations management field. Its applications range from supply chain design (see among others Creazza, Dallari, and Rossi (2012a, 2012b) to master production schedule (see e.g. Chase, Aquilano, and Jacobs 1998). Several authors considered LP as a useful tool also to improve MRP procedures.

Billington, Mcclain, and Thomas (1983) proposed a mixed integer LP (MRP-ILP) model to minimise workforce and stock holding costs. At the beginning, a 'minimum' lead-time is defined, that does not include the delays - if any - due 
to capacity constraints. Indeed, the MRP-ILP model calculates these delays implicitly. Interestingly, to reduce the mixed integer problem in the size while keeping optimality, these authors introduced some techniques of product structure compression. Nevertheless, MRP-ILP remains a complex model: stock levels are calculated at each step, which requires huge computational efforts in real-life problems (Jodlbauer and Reitner 2012). Moreover, lead time is often considered as an exogenous parameter independent of workload (Kacar and Uzsoy 2014).

Ornek and Cengiz (2006) proposed a three-step algorithm that combines LP with the traditional BOM explosion to generate a capacity-feasible schedule. Once a plan has been developed via traditional MRP procedure (hence with predefined lead times), LP is used to check capacity feasibility by appropriately shifting backward over time some production lots that exceed the available capacity.

Mula, Poler, and Garcia (2006) firstly introduced a LP model that considers capacity constraints. Then, they developed three models based on objective functions that take into account - as fuzzy variables (see e.g. Cigolini and Rossi 2008) - stock keeping costs, market demand and production capacity. These authors claimed that the proposed models were applied to a real-life company. However, while the model is supposed to support decision-makers in simulating scenarios or for rescheduling purposes, the authors could not properly customise the three models and they applied them just to one finished product.

Öztürk and Örnek (2012) developed a Capacity Allocator Scheduler coupled with a mixed-integer heuristic, which allows minimising stock holding costs and the use of external capacity (outsourcing). Lead-times are constant so the quality of the solution is tightly linked to the likelihood of the pre-defined manufacturing and replenishment lead times.

\subsection{Approaches based on simulation}

There are a number of studies to be found in the literature where simulation models are connected with an optimisation algorithm (Gansterer, Almeder, and Harti 2014). As well, a number of authors have proposed iterative algorithms that combine LP models using fixed lead times with a simulation model (Kacar and Uzsoy 2014). Simulative methods refer to techniques aimed at integrating MRP procedure with simulation tools, so that the actual lead times can be determined by taking into account the capacity constraints in the simulation model.

Weintraub, Zozom, Hodgson, and Cormier (1997) integrated an infinite-capacity MRP with a simulation-based scheduling system. Starting from the plan of orders (coming from the MRP procedure), the scheduling system calculates the lead-times by assigning jobs to resources, beginning with the lowest-slack job (the slack is defined as the difference between the job's due date and the sum of its waiting and working times). Then, the estimated lead-times are used as inputs of the infinite-capacity MRP procedure in a recurrent way, until a MRP plan consistent with the schedule is gotten.

In a similar way, Rossi and Pero (2011) considered the net requirements at the highest level of the BOM and employed a simulation model of the production process to assign to the resources all the orders for all the items at all the BOM levels. Then, by applying appropriate right-shifts (shifts of lots backward over time), the plan that minimises stocks and WIP is obtained.

\subsection{A taxonomy}

So far, the literature review has pointed out that the debate about the way capacity constraints should be taken into account along the MRP planning phase is still open, and the proposed approaches by several authors still have some limits. Table 1 presents a taxonomy of the literature.

Lead time as input is a relevant variable as it states whether lead time is a fixed value input of the procedure or not. Capacity constraint is relevant as well, since capacity constraints can be embedded in the proposed procedure (in process), or they can be considered only after the traditional MRP procedure has been run (post process) or even evaluated level by level of the BOM (Level by level), or just for some levels or only for bottleneck machines. Lot sizes can be either requested as input by the procedure (fixed) or output of the procedure (variable), sometimes subject to some constraints (constrained). Finally, the model can be tested via data generated by authors (example) or through data from real-life production systems (real case)

Whilst capacity and lead time are tightly linked one another through the Little's law (Little 1961), lead time is considered by most approaches as fixed input to the MRP procedure. Moreover, some methods are unable to check the capacity-related constraints at each level of the BOM, thus leading to infeasible plans for components or materials. Some other methods check capacity-related constraints level by level, thus leading to solutions that are locally (i.e. at each level) optimal, but not optimal for the entire BOM. Finally, the applicability in field to real-life companies has not been reported for many methods. 


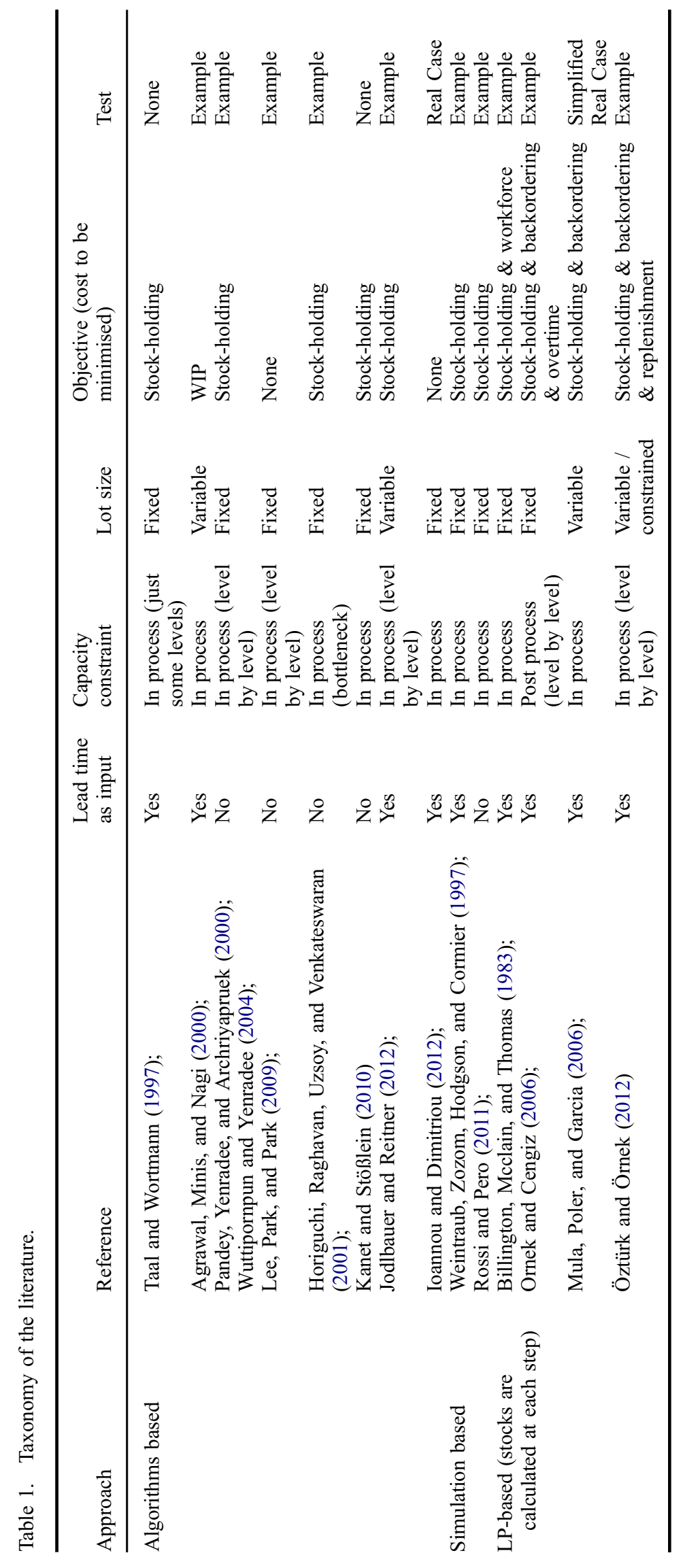


The research work outlined here tried to overcome some of the limits above: the new proposed finite capacity MRP procedure does not consider lead times as input, it evaluates capacity-related constraints at all level of the BOM at the same time and it has been tested in a real-life industrial context.

\section{Methodology}

The procedure proposed here is based on a combination of the traditional infinite-capacity MRP and a MILP approach.

The manufacturing environment is made up from a number of capacitated production resources $\left(\mathrm{R}_{f, r}\right)$ focused on a family of products $\left(\mathrm{S}_{f}\right)$. All the resources belonging to a given products family can manufacture all the finished products (belonging to the corresponding family) and all the semi-finished products they are composed of. Both finished products and semi-finished products are defined as $\mathrm{P}_{f, i}$ (where $i$ is the index of the item belonging to family $f$ ) and they are manufactured according to a given lot-size $\left(\operatorname{lot}_{f, i}\right)$. Each item is characterised by a given cycle time on each resource of the corresponding family $\left(\mathrm{ct}_{f, i, r}\right)$.

In short, within the new methodology proposed here, the steps outlined below are followed.

(1) The traditional MRP procedure allows to calculate the net requirements (including waste, $\mathrm{NReqW}_{f, i, t}$ ) for all the time buckets $(t)$ of the horizon for all the finished products and the number of lots to be ordered for each purchased component in each time bucket.

(2) The MILP model allows to calculate the net requirements (including waste, $\mathrm{NReqW}_{f, i, t}$ ) of semi-finished products and the number of lots to be ordered for each finished and semi-finished product in each time bucket $\left(X_{f, i, t}\right)$.

\subsection{Input data}

The proposed model requires some input data below summarised.

(1) The BoM of each finished product, together with the indication whether each component is manufactured in-house (i.e. it is a semi-finished product) or it is outsourced (i.e. it is purchased from an external supplier) and the coefficient of use $\left(\mathrm{u}_{f, i, j}\right)$ that pegs item $\mathrm{P}_{f, i}$ to the corresponding parent item $\mathrm{P}_{f, j}$ including scraps (if any).

(2) The gross requirements $\left(\mathrm{GReq}_{f, i, t}\right)$ of each finished product $\left(\mathrm{P}_{f, i}\right)$ in each time bucket $(t)$ of the horizon.

(3) The demand $\left(\mathrm{D}_{f, i, t}\right)$ coming from outside the production system (e.g. in case the semi-finished product is sold as a spare part) of each semi-finished product $\left(\mathrm{P}_{f, i}\right)$ in each time bucket $(t)$ of the horizon.

(4) The initial (i.e. at the beginning of the planning horizon) availability of each finished product, each semi-finished product and each purchased component $\left(\mathrm{A}_{f, i, 1}\right)$ given by its initial inventory level reduced by committed inventory and safety stocks.

(5) The percentage of waste $\left(\mathrm{w}_{f, i}\right)$ of each finished and semi-finished product $\left(\mathrm{P}_{f, i}\right)$.

(6) The set of resources $\left(\mathrm{R}_{f, r}\right)$ that can process each finished and semi-finished product.

(7) The cycle time $\left(\mathrm{ct}_{f, i, r}\right)$ spent by each finished and semi-finished product on the resource $\left(\mathrm{R}_{f, r}\right)$ where it is manufactured.

(8) The production capacity $\left(\mathrm{pc}_{f, r, t}\right.$, measured in hours) for each resource $\left(\mathrm{R}_{f, r}\right)$ and each time bucket $(t)$ of the horizon.

\subsection{The proposed method}

As stated above, the proposed method is based on a combination of traditional MRP and MILP. In particular, for each finished and semi-finished product, the MRP table is outlined by Equations (1)-(7), while for each purchased component the used MRP table is the traditional one.

In case of finished products, gross requirements are given, while in case of semi-finished products, they are calculated according to Equation (1).

$$
\left.\operatorname{GReq}_{f, i, t}=\sum_{j \neq i} \mathrm{X}_{f, j, t} \cdot \operatorname{lot}_{f, j} \cdot \mathrm{u}_{f, i, j}\right)+\mathrm{D}_{f, i, t} \quad \forall f, \forall i, \forall t,
$$

where $\mathrm{X}_{f, j, t}$ represents the number of ordered lots to satisfy the requirements of finished products and $\operatorname{lot}_{f, j}$ represents the lot size. $\mathrm{u}_{f, i, j}$ represents the coefficient of use that pegs item $\mathrm{P}_{f, i}$ to the corresponding parent item $\mathrm{P}_{f, j}$ including scraps 
(if any). $\mathrm{D}_{f, i, t}$ represents the demand coming from outside the production system (e.g. in case the semi-finished product is sold as a spare part) of each semi-finished product $\left(\mathrm{P}_{f, i}\right)$ in each time bucket $(t)$.

Equations (2)-(7) give respectively: availability, net requirements, net requirements and wastes, net requirements and wastes as number of lots, cumulative net requirements and wastes as number of lots and cumulative number of lots.

$$
\begin{gathered}
A_{f, i, t}=\max \left(0, A_{f, i, t-1}-\mathrm{GReq}_{f, i, t-1}\right) \quad \forall f, \forall i, \forall t, \\
\mathrm{NReq}_{f, i, t}=\max \left(0, \operatorname{GReq}_{f, i, t}-A_{f, i, t}\right) \\
\mathrm{NReqW}_{f, i, t}=\operatorname{NReq}_{f, i, t} \cdot\left(1+\mathrm{w}_{f, i}\right) \quad \forall f, \forall i, \forall t, \\
\operatorname{NReqWLot}_{f, i, t}=\frac{\operatorname{NReqW}_{f, i, t}}{\operatorname{lot}_{f, i}} \quad \forall f, \forall i, \forall t, \forall t, \\
\operatorname{CumNReqWLot}_{f, i, t}=\sum_{k=1}^{t} \operatorname{NReqWLot}_{f, i, k} \quad \forall f, \forall i, \forall t, \\
\operatorname{CumOrder}_{f, i, t}=\sum_{k=1}^{t} X_{f, i, k} \quad \forall f, \forall i, \forall t .
\end{gathered}
$$

In particular, MILP is applied only to Equations (5), (6) and (7), where purchased components are not taken into account in that they do not absorb production capacity of any modelled resource. Therefore, MILP allows calculating the number of lots to be ordered for each finished and semi-finished product in each time bucket $(t)$ in such a way: (i) to comply with the production capacity of each resource; (ii) to minimise the cost of holding stock; (iii) to cover the net requirements and wastes.

\subsection{MILP model}

The minimisation of the cost of holding stock mentioned above is obtained by calculating the integer decision variables $X_{f, i, t}$. The objective function is given by Equation (8).

$$
\min \sum_{f} \sum_{i} \sum_{t} X_{f, i, t} \cdot \mathrm{FC}_{t},
$$

where $\mathrm{FC}_{t} \mathrm{~s}$ represent fictitious costs set so that:

$$
\mathrm{FC}_{t}>\mathrm{FC}_{t+1} \quad \forall t
$$

Because of (9), the objective function (8) delays the manufacturing activities as much as possible, thus minimising the cost of holding stock, without explicitly calculating the amount of stocks at the end of each time bucket of the planning horizon. (10) and (11) give the constraints of the model.

$$
\begin{array}{cc}
\operatorname{CumOrder}_{f, i, t} \geq \operatorname{CumNReqWLot}_{f, i, t} & \forall f, \forall i, \forall t \\
\sum_{i} \mathrm{X}_{f, i, t} \cdot \operatorname{lot}_{f, i, t} \cdot \mathrm{ct}_{f, i, r} \leq \mathrm{pc}_{f, r, t} \quad \forall r, \forall t
\end{array}
$$

Equation (10) makes sure that the net requirements are fulfilled, since the sum of the ordered lots for each finished and semi-finished product must be equal or greater than the sum of the net requirements and wastes (expressed as number of lots). Equation (11) makes sure that the lots (i.e. the workload) released to each resource in each time bucket do not exceed the production capacity of the corresponding resource. The sum of the production hours of resource $R_{f, r}$ required by the ordered lots of all the finished and semi-finished products belonging to family $f$ must not be greater than the production capacity of resource $R_{f, r}$ in each time bucket $t$. 


\section{Case study}

The proposed model has been applied to a real-life company (hereinafter referred to as CML) manufacturing manual valve actuators, designed to provide the force of torque to operate valves, in order to modulate the fluid flow. CML is the Italian branch of a multinational group, leader in the valve actuators market, and it is specialised in manual valve actuators, widely employed in oil and gas industry, in water distribution and treatment, and in chemical processing. The planning process of CML is complex, due to the high number of finished products, each of them with at least four levels in its BOM, and to the importance of capacity constraints, in that CML manufactures and assembles many components in house.

Data regarding a family (called M Series) composed of eleven actuators (finished products) was gathered through several company visits, by interviewing plant managers and production planners, by analysing company documents and by extracting information from the company Enterprise Resources Planning (ERP) system. Figure 1 provides an example of a manual valve actuator belonging to $\mathrm{M}$ Series.

All the M Series actuators have a cover (see ' 1 ' in Figure 1), a gear case (see '2' in Figure 1), a quadrant (see '4' in Figure 1) and a worm shaft (see ' 5 ' in Figure 1). The finished products belonging to $M$ series differ from one another by the maximum output torque, by the input torque, by the turns to close, and by the size of the mounting flange.

On the other hand, the components of each finished product are different in size and in number (ranging from 17 to 27), since e.g. some actuators have an additional input pinion and a spur wheel to provide higher torque. Table 2 shows that the complexity of $\mathrm{M}$ series family is comparable to the one reported by other similar studies.

Figure 2 depicts the BOM of a typical finished product belonging to M Series.

Table 3 shows the cycle times of the four different semi-finished products (turned quadrant, broached quadrant, drilled gear case and drilled cover), for all finished products (M10, M12, M14, M15, M16, M20, M30, M40, M55, M60 and M70 actuators, where M identifies the series and the number the size of the actuator).

The cover, the gear case and the quadrant are manufactured from blanks (purchased from external suppliers). The manufacturing process takes place in a job shop where blanks are drilled (to get the drilled cover and the drilled gear case), and turned and broached (to get the turned quadrant and the broached quadrant respectively). All the other components are bought from external suppliers. Then, the assembly is performed internally through assembly cells: each cell

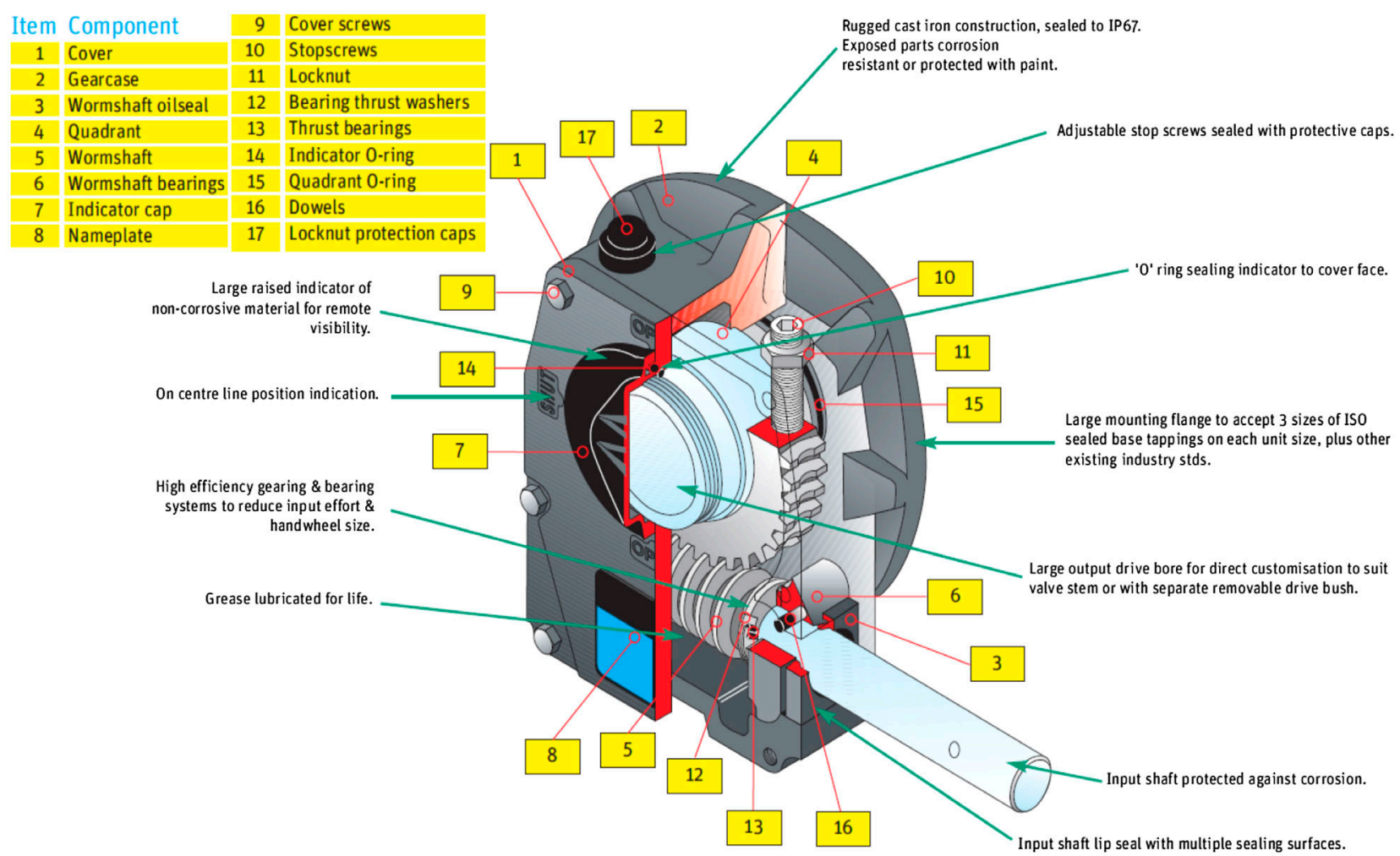

Figure 1. Example of a manual valve actuator belonging to M Series. 
Table 2. Complexity of $\mathrm{M}$ series family compared to other studies in the same field.

\begin{tabular}{|c|c|c|c|c|c|c|}
\hline Paper & This one & $\begin{array}{l}\text { Rossi and } \\
\text { Pero (2011); }\end{array}$ & $\begin{array}{l}\text { Nagendra and } \\
\text { Das (2001) }\end{array}$ & Enns (2001) & $\begin{array}{l}\text { Agrawal, Minis, } \\
\text { and Nagi (2000); }\end{array}$ & $\begin{array}{l}\text { Molinder and } \\
\text { Olhager (1998) }\end{array}$ \\
\hline Finished products (\#) & 11 & 2 & 3 & 2 & 1 & 1 \\
\hline Items $(\#)$ & 55 & 6 & 20 & 8 & 8 & 3 \\
\hline BoM levels (\#) & 4 & 4 & 3 & 3 & 4 & 3 \\
\hline Machines (\#) & 4 & 3 & 6 & 5 & 2 & 2 \\
\hline Shared machines & yes & yes & Yes & yes & Yes & No \\
\hline Shared components & yes & yes & Yes & yes & No & No \\
\hline Same items@different levels of the BoM & no & yes & No & No & No & No \\
\hline Orders in progress & n.a. & yes & No & yes & No & No \\
\hline
\end{tabular}

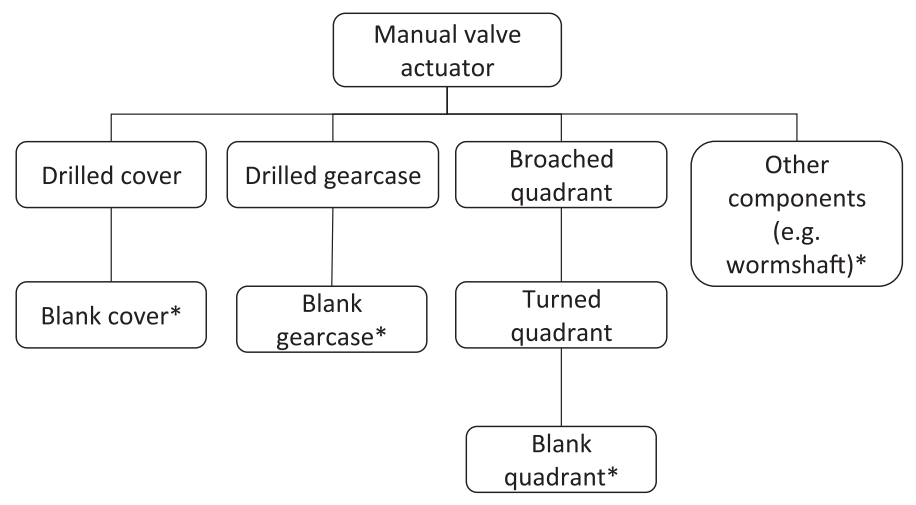

Key: ${ }^{*}=$ item purchased from external suppliers

Figure 2. BOM of an actuator belonging to $\mathrm{M}$ series.

Table 3. Cycle times (in min/pcs) of the 4 semi-finished products composing the 11 finished products belonging to the 'M' series.

\begin{tabular}{|c|c|c|c|c|}
\hline Finished product & Turned (lathed) quadrant & Broached quadrant & Drilled gear case & Drilled cover \\
\hline $\mathrm{P}_{\mathrm{M}, 10 \_\mathrm{MVA}}$ & 10 & 2 & 5 & 1 \\
\hline $\mathrm{P}_{\mathrm{M}, 12 \mathrm{MVA}}$ & 10 & 2 & 5 & 1 \\
\hline $\mathrm{P}_{\mathrm{M}, 14 \text { MVA }}$ & 10 & 2 & 5 & 1 \\
\hline $\mathrm{P}_{\mathrm{M}, 15 \text { MVA }}$ & 10 & 2 & 5 & 1 \\
\hline $\mathrm{P}_{\mathrm{M}, 16 \text { - MVA }}$ & 10 & 2 & 5 & 1 \\
\hline $\mathrm{P}_{\mathrm{M}, 20 \text { MVA }}$ & 10 & 4 & 13 & 2 \\
\hline $\mathrm{P}_{\mathrm{M}, 30 \_\mathrm{MVA}}$ & 30 & 70 & 13 & 2 \\
\hline $\mathrm{P}_{\mathrm{M}, 40 \text { MVA }}$ & 35 & 90 & 14 & 2 \\
\hline $\mathrm{P}_{\mathrm{M}, 55 \text {, }}$ & 40 & 90 & 15 & 2 \\
\hline $\mathrm{P}_{\mathrm{M}, 60 \_\mathrm{MVA}}$ & - & 90 & 7 & 3 \\
\hline $\mathrm{P}_{\mathrm{M}, 70 \_\mathrm{MVA}}$ & - & 90 & 7 & 3 \\
\hline
\end{tabular}

of the plant is devoted to a specific family (series) of actuators; therefore, a specific cell is devoted to M series. Drills, lathes, broaches and assembly cells are available on a daily basis of one 8-hour shift.

Hereinafter, $M$ represents the family index, while the product index is as follows. A figure (e.g. 16) identifies the size of the corresponding actuator, followed by some capital letters, which pinpoint the type of the considered item: MVA means the actuator, TQ means the turned quadrant, BQ means the broached quadrant, DG means the drilled gear case and DC means the drilled cover.

The planning horizon comprises 25 buckets, corresponding to 5 weeks, 5 working days each. The gross requirements - i.e. the demand - of the finished products that feed the MRP procedure are the same for each product and equal to 
100 pieces over week 1, 200 pieces over week 2, 150 pieces over week 3, 200 pieces over week 4 and 150 pieces over week 5 .

Gross requirements are assumed the same for each one of the 11 finished products, while there are no gross requirements for components, since they do not face external demand.

Inventory, committed inventory, safety stocks, waste and lot sizes are, accordingly, 300 pieces, 50 pieces, 50 pieces, $0 \%$ and 100 pieces for the actuators, while for the drilled covers (the semi-finished products for which next section presents the MRP tabels) are, accordingly, 300 pieces, 0 pieces, 50 pieces, $0 \%$ and 50 pieces. According to (9), the fictitious costs are set 10,000,1000,100,10 and 1 for week 1 , week 2 , week 3 , week 4 and week 5 , respectively.

\section{Results}

The application of the new capacity-constrained MRP approach to the M series family of actuators produces 55 MRP tables. 11 MRP tables are related to the actuators: each table is related to one actuator (finished product) belonging to the considered family. 44 more MRP tables are related to components: each table is related to each one of the four semi-finished products pegged to each finished product. For the sake of simplicity, just 2 MRP tables are presented here: one for a finished product, namely the M10 actuator ( $\mathrm{P}_{\mathrm{M}, 10 \text { MVA }}$, see Table 4) and one for a semi-finished product, namely the M10 drilled cover ( $\mathrm{P}_{\mathrm{M}, 10 \_\mathrm{C}}$, see Table 5).

Table 4 clearly indicates that rows A to $\mathrm{F}$ are filled with figures, while row $\mathrm{G}$ (number of ordered lots) and $\mathrm{H}$ (cumulated number of ordered lots) are left parametric, since they will be filled with the results of the MILP phase. In a similar way, all the rows of Table 5 - which represents the MRP table of a semi-finished product - are all set parametric as well. This is due to that row A of Table 5 links (as under the traditional MRP procedure) the gross requirements of the semi-finished product (the M10 drilled cover) to the number of ordered lots of the corresponding parent item (the M10 actuator, which is a finished product).

The number of ordered lots for each finished and semi-finished product in each time bucket $\left(\mathrm{X}_{f, i, t}\right)$ is obtained through MILP, using the objective function expressed by Equation (8). As stated in Section 4, outsourced components do not take part in the MILP model, as their procurement does not absorb capacity.

The constraints of the model are presented in Tables 6 and 7. In particular, Table 6 outlines the fulfilment of requirements of the M10 manual valve actuator (finished product). Table 7 shows the capacity constraint fulfilment referring to week $1(t=1)$. For each set of machines, the capacity utilisation is calculated by summing up, bucket by bucket of the horizon, the production time required (calculated based on cycle times, lot sizes and ordered lots) by finished and semifinished products in the considered period. The available capacity of each production resource for each bucket (period $t$ ) accounts for 48,000 minutes.

Table 4. MRP table of M10 actuator (finished product).

\begin{tabular}{|c|c|c|c|c|c|c|}
\hline \multicolumn{2}{|c|}{ Row } & \multirow{2}{*}{$\frac{\text { Week } 1}{100}$} & \multirow{2}{*}{$\frac{\text { Week } 2}{200}$} & \multirow{2}{*}{$\frac{\text { Week } 3}{150}$} & \multirow{2}{*}{$\frac{\text { Week } 4}{200}$} & \multirow{2}{*}{$\frac{\text { Week } 5}{150}$} \\
\hline A & $\begin{array}{l}\text { Gross requirements } \\
\left(\text { GReq } q_{M, 10} \text { MVA,t }\right)\end{array}$ & & & & & \\
\hline B & Availability $\left(\mathrm{A}_{\mathrm{M}, 10 \_\mathrm{MVA}, \mathrm{t}}\right)$ & 200 & 100 & 0 & 0 & 0 \\
\hline $\mathrm{C}$ & $\begin{array}{l}\text { Net requirements } \\
\left(\mathrm{NReq}_{\mathrm{M}, 10 \_\mathrm{MVA}, \mathrm{t}}\right)\end{array}$ & 0 & 100 & 150 & 200 & 150 \\
\hline $\mathrm{D}$ & $\begin{array}{l}\text { Net requirements and } \\
\text { wastes }\left(\mathrm{NReq}_{\mathrm{M}, 10 \_\mathrm{MVA}, \mathrm{t}}\right)\end{array}$ & 0 & 100 & 150 & 200 & 150 \\
\hline $\mathrm{E}$ & $\begin{array}{l}\text { Net requirements and } \\
\text { wastes as number of lots } \\
\left(\text { NReqWLot }_{\mathrm{M}, 10 \_\mathrm{MVA}, \mathrm{t}}\right)\end{array}$ & 0 & 1 & 1,5 & 2 & 1,5 \\
\hline $\mathrm{F}$ & $\begin{array}{l}\text { Cumulative net } \\
\text { requirements and wastes as } \\
\text { number of lots } \\
\left(\text { CumNReqWLot }_{\mathrm{M}, 10 \_M V A, t}\right)\end{array}$ & 0 & 1 & 2,5 & 4,5 & 6 \\
\hline G & $\begin{array}{l}\text { Number of ordered lots } \\
\left(X_{M, 10 \_M V A, t}\right)\end{array}$ & $\mathrm{X}_{\mathrm{M}, 10 \_\mathrm{MVA}, 1}$ & $\mathrm{X}_{\mathrm{M}, 10 \_\mathrm{MVA}, 2}$ & $\mathrm{X}_{\mathrm{M}, 10 \_\mathrm{MVA}, 3}$ & $\mathrm{X}_{\mathrm{M}, 10 \_\mathrm{MVA}, 4}$ & $\mathrm{X}_{\mathrm{M}, 10 \_ \text {MVA }, 5}$ \\
\hline $\mathrm{H}$ & $\begin{array}{l}\text { Cumulative number of } \\
\text { ordered lots } \\
\left(\text { CumOrder }_{M, 10 \_M V A, t}\right)\end{array}$ & $\sum_{t=1}^{1} \mathrm{X}_{\mathrm{M}, 10 \_\mathrm{MVA}, \mathrm{t}}$ & $\sum_{t=1}^{2} \mathrm{X}_{\mathrm{M}, 10 \_\mathrm{MVA}, \mathrm{t}}$ & $\sum_{t=1}^{3} \mathrm{X}_{\mathrm{M}, 10 \_\mathrm{MVA}, \mathrm{t}}$ & $\sum_{t=1}^{4} \mathrm{X}_{\mathrm{M}, 10 \_\mathrm{MVA}, \mathrm{t}}$ & $\sum_{t=1}^{5} \mathrm{X}_{\mathrm{M}, 10 \_\mathrm{MVA}, \mathrm{t}}$ \\
\hline
\end{tabular}




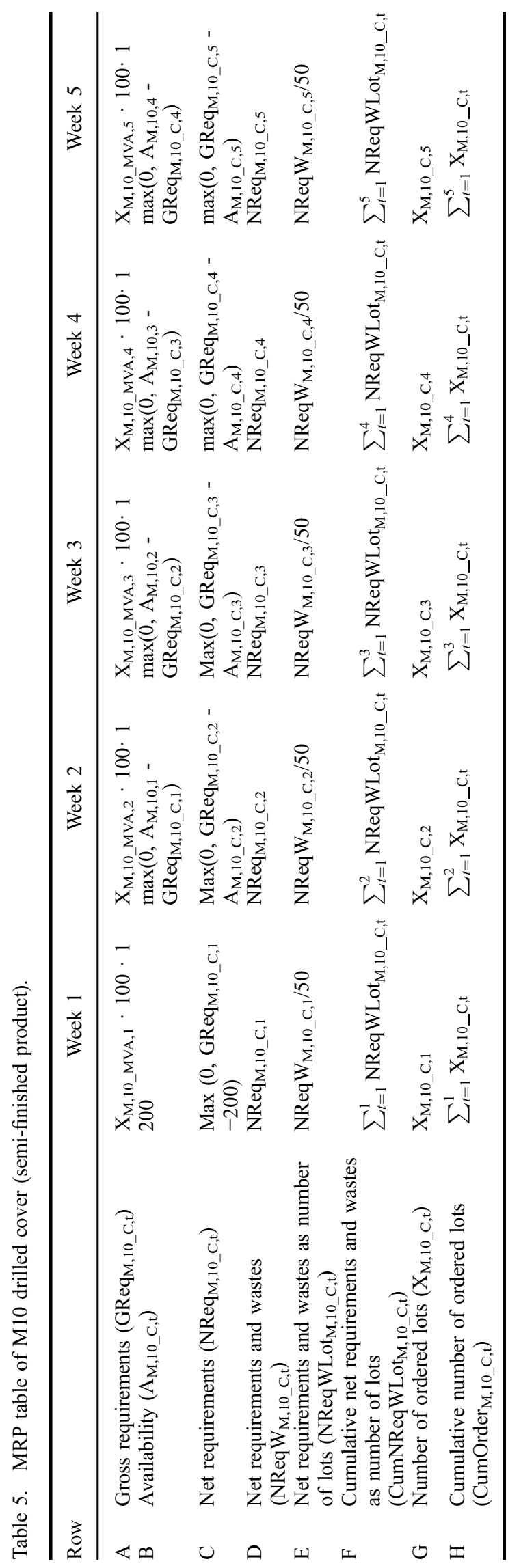


Table 6. Fulfilment of M10 actuator requirements (' $\leq$ ' means that the values in row 2 must be less or equal than the values in row 4).

\begin{tabular}{|c|c|c|c|c|c|}
\hline & Week 1 & Week 2 & Week 3 & Week 4 & Week 5 \\
\hline $\begin{array}{l}\text { Cumulative net requirements }+ \\
\text { wastes in number of lots } \\
\left(\text { CumNReqWLot }_{\mathrm{M}, 10 \text { MVA,t }}\right)\end{array}$ & 0 & 1 & 2,5 & 4,5 & 6 \\
\hline Constraint & $\leq$ & $\leq$ & $\leq$ & $\leq$ & $\leq$ \\
\hline 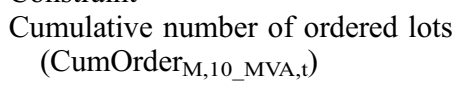 & $\sum_{t=1}^{1} \mathrm{X}_{\mathrm{M}, 10 \_\mathrm{MVA}, \mathrm{t}}$ & $\sum_{t=1}^{2} \mathrm{X}_{\mathrm{M}, 10 \_\mathrm{MVA}, \mathrm{t}}$ & $\sum_{t=1}^{3} \mathrm{X}_{\mathrm{M}, 10 \_\mathrm{MVA}, \mathrm{t}}$ & $\sum_{t=1}^{4} \mathrm{X}_{\mathrm{M}, 10 \_\mathrm{MVA}, \mathrm{t}}$ & $\sum_{t=1}^{5} \mathrm{X}_{\mathrm{M}, 10 \_\mathrm{MVA}, \mathrm{t}}$ \\
\hline
\end{tabular}

Table 7. Capacity constraint fulfilment in week 1 (' $\leq$ ' means that the values in row 2 must be less or equal than the values in row 4 ).

\begin{tabular}{|c|c|c|c|c|}
\hline Product & Assembly cell & Lathe & Broach & Drill \\
\hline $\begin{array}{l}\text { Required } \\
\text { capacity } \\
\text { (min) }\end{array}$ & $15 \cdot 100 \cdot \sum_{i=10 \_ \text {MVA }}^{70 \_ \text {MVA }} \mathrm{X}_{\mathrm{M}, i, 1}$ & $\begin{array}{l}10 \cdot 100 \cdot \sum_{i=10 \_}^{20}{ }^{\mathrm{TQ}} \mathrm{X}_{\mathrm{M}, i, 1} \\
+30 \cdot 100 \cdot \mathrm{X}_{\mathrm{M}, 10}{ }_{\mathrm{TQ}, 1} \\
+35 \cdot 100 \cdot \mathrm{X}_{\mathrm{M}, 40 \_}{ }_{\mathrm{TQ}, 1} \\
+40 \cdot 100 \cdot \mathrm{X}_{\mathrm{M}, 55}{ }_{\mathrm{TQ}, 1}\end{array}$ & $\begin{array}{l}2 \cdot 100 \cdot \sum_{i=10 \_\mathrm{BQ}}^{16 \_\mathrm{BQ}} \mathrm{X}_{\mathrm{M}, i, 1} \\
+4 \cdot 100 \cdot \mathrm{X}_{\mathrm{M}, 20 \_\mathrm{BQ}, 1} \\
+70 \cdot 100 \cdot \mathrm{X}_{\mathrm{M}, 30 \_\mathrm{BQ}, 1} \\
+90 \cdot 100 \cdot \sum_{i=40 \_\mathrm{BQ}}^{70 \_\mathrm{BQ}} \mathrm{X}_{\mathrm{M}, i, 1}\end{array}$ & $\begin{array}{l}5 \cdot 70 \cdot \sum_{i=10 \_\mathrm{DG}}^{16 \_\mathrm{DG}} \mathrm{X}_{\mathrm{M}, i, 1} \\
+13 \cdot 70 \cdot \sum_{i=20 \_\mathrm{DG}}^{30 \_\mathrm{DG}} \mathrm{X}_{\mathrm{M}, i, 1} \\
+14 \cdot 70 \cdot \mathrm{X}_{\mathrm{M}, 40 \_\mathrm{DG}, 1} \\
+7 \cdot 70 \cdot \sum_{i=60 \_\mathrm{DG}}^{70 \_ \text {DG }} \mathrm{X}_{\mathrm{M}, i, 1} \\
+1 \cdot 50 \cdot \sum_{i=10 \_\mathrm{DG}}^{16} \mathrm{X}_{\mathrm{M}, i, 1} \\
+2 \cdot 50 \cdot \sum_{i=20 \_\mathrm{DG}}^{55 \_ \text {DG }} \mathrm{X}_{\mathrm{M}, i, 1} \\
+3 \cdot 50 \cdot \sum_{i=60 \_\mathrm{DG}}^{70 \_ \text {DG }} \mathrm{X}_{\mathrm{M}, i, 1}\end{array}$ \\
\hline Constraint & $\leq$ & $\leq$ & $\leq$ & $\leq$ \\
\hline $\begin{array}{l}\text { Available } \\
\text { capacity } \\
\text { (min) }\end{array}$ & 48,000 & 48,000 & 48,000 & 48,000 \\
\hline
\end{tabular}

The MILP model has been solved through Analytic Solver Platform (a software by Frontline Solver) and the computing time is less than 3 minutes. Tables 8 and 9 show the 'solved' MRP tables respectively of the M10 actuator (finished product) and M10 drilled cover (semi-finished product). Figures filling rows F and H of Tables 8 and 9 show, respectively, that M10 actuator's and M10 drilled cover's requirements are met: for each week, the cumulative net requirements and wastes as number of lots is smaller or equal to the cumulative number of ordered lots. As for the capacity constraint, over week 1 the broach is the sole working resource, whose capacity is absorbed by the quadrants of M30, M40, M55 and M70 actuators that require 7,000, 9,000, 9,000 and 9,000 minutes (units of time) respectively and 34,000 minutes on the whole, thus quite far from the broach capacity $(48,000$ minutes).

The finite-capacity approach introduced in this paper is remarkably different from many models proposed in literature and based on LP, MILP or some other programming algorithms. Indeed, MILP problem here is significantly reduced in its complexity since the output of the model does not consist in the whole MRP table: it merely consists in the (limited) portion of the MRP table impacted by facilities capacity. This allows reducing the computational burden even when dealing with real-life problems - without having to resort to sophisticated heuristic algorithms, which usually operate in a recurrent way: they receive lead-times as inputs and they convert an initially infeasible solution (where the capacity constraint has been relaxed) into a feasible one by adding the capacity limit step-by-step. Besides, the new model introduced here does not require lead times as inputs. 
Table 8. MRP table of M10 actuator (finished product) after MILP.

\begin{tabular}{|c|c|c|c|c|c|c|}
\hline $\begin{array}{l}\text { Row (see } \\
\text { Table 1) }\end{array}$ & & $\begin{array}{c}\text { Week } \\
1\end{array}$ & $\begin{array}{l}\text { Week } \\
2\end{array}$ & $\begin{array}{l}\text { Week } \\
3\end{array}$ & $\begin{array}{l}\text { Week } \\
4\end{array}$ & $\begin{array}{c}\text { Week } \\
5\end{array}$ \\
\hline A & Gross requirements $\left(\mathrm{GReq}_{\mathrm{M}, 10 \mathrm{MVA}, \mathrm{t}}\right)$ & 100 & 200 & 150 & 200 & 150 \\
\hline $\mathrm{B}$ & Availability $\left(\mathrm{A}_{\mathrm{M}, 10 \_\mathrm{MVA}, \mathrm{t}}\right)$ & 200 & 100 & 0 & 0 & 0 \\
\hline $\mathrm{C}$ & Net requirements $\left(\mathrm{NReq}_{\mathrm{M}, 10} \mathrm{MVA}, \mathrm{t}\right)$ & 0 & 100 & 150 & 200 & 150 \\
\hline $\mathrm{D}$ & Net requirements and wastes $\left(\mathrm{NReqW}_{\mathrm{M}, 10 \_\mathrm{MVA}, \mathrm{t}}\right)$ & 0 & 100 & 150 & 200 & 150 \\
\hline $\mathrm{E}$ & Net requirements and wastes as number of lots $\left(\right.$ NReqWLot $\left._{M, 10 \_M V A, t}\right)$ & 0 & 1 & 1.5 & 2 & 1.5 \\
\hline $\mathrm{F}$ & $\begin{array}{l}\text { Cumulative net requirements and wastes as number of lots } \\
(\text { CumNReqWLot } \\
\mathrm{M}, 10 \text { MVA,t }\end{array}$ & 0 & 1 & 2.5 & 4.5 & 6 \\
\hline G & Number of ordered lots $\left(\mathrm{X}_{\mathrm{M}, 10 \mathrm{MVA}, \mathrm{t}}\right)$ & 0 & 1 & 2 & 2 & 1 \\
\hline $\mathrm{H}$ & Cumulative number of ordered lots (CumOrder ${ }_{M, 10 \_M V A, t}$ ) & 0 & 1 & 3 & 5 & 6 \\
\hline
\end{tabular}

Table 9. MRP table of M10 drilled cover (semi-finished product) after MILP.

\begin{tabular}{|c|c|c|c|c|c|c|}
\hline $\begin{array}{l}\text { Row (see } \\
\text { Table 1) }\end{array}$ & & $\begin{array}{c}\text { Week } \\
1\end{array}$ & $\begin{array}{l}\text { Week } \\
2\end{array}$ & $\begin{array}{l}\text { Week } \\
3\end{array}$ & $\begin{array}{l}\text { Week } \\
4\end{array}$ & $\begin{array}{l}\text { Week } \\
5\end{array}$ \\
\hline A & Gross requirements $\left(\mathrm{GReq}_{\mathrm{M}, 10 \_\mathrm{MVA}, \mathrm{t}}\right)$ & 0 & 100 & 200 & 200 & 100 \\
\hline $\mathrm{B}$ & Availability $\left(\mathrm{A}_{\mathrm{M}, 10 \_\mathrm{MVA}, \mathrm{t}}\right)$ & 250 & 250 & 150 & 0 & 0 \\
\hline $\mathrm{C}$ & Net requirements $\left(\mathrm{NReq}_{\mathrm{M}, 10 \_\mathrm{MVA}, \mathrm{t}}\right)$ & 0 & 0 & 50 & 200 & 100 \\
\hline $\mathrm{D}$ & Net requirements and wastes $\left(\mathrm{NReqW}_{\mathrm{M}, 10 \_\mathrm{MVA}, \mathrm{t}}\right)$ & 0 & 0 & 50 & 200 & 100 \\
\hline $\mathrm{E}$ & Net requirements and wastes as number of lots $\left(\right.$ NReqWLot $\left._{M, 10 \_M V A, t}\right)$ & 0 & 0 & 1 & 4 & 2 \\
\hline $\mathrm{F}$ & $\begin{array}{l}\text { Cumulative net requirements and wastes as number of lots } \\
\left(\text { CumNReqWLot }_{M, 10 \_M V A, t}\right)\end{array}$ & 0 & 0 & 1 & 5 & 7 \\
\hline G & Number of ordered lots $\left(\mathrm{X}_{\mathrm{M}, 10 \_\mathrm{MVA}, \mathrm{t}}\right)$ & 0 & 0 & 1 & 4 & 2 \\
\hline $\mathrm{H}$ & Cumulative number of ordered lots (CumOrder $\left.{ }_{M, 10 \_M V A, t}\right)$ & 0 & 0 & 1 & 5 & 7 \\
\hline
\end{tabular}

Table 10. Orders of the broached quadrant and capacity of the broach.

\begin{tabular}{|c|c|c|c|c|c|c|}
\hline & Available capacity (min) & $\begin{array}{l}\text { Week } 1 \\
48,000\end{array}$ & $\begin{array}{l}\text { Week } 2 \\
48,000\end{array}$ & $\begin{array}{l}\text { Week } 3 \\
48,000\end{array}$ & $\begin{array}{l}\text { Week } 4 \\
48,000\end{array}$ & $\begin{array}{l}\text { Week } 5 \\
48,000\end{array}$ \\
\hline & Orders (\#) & & & & & \\
\hline \multirow[t]{13}{*}{ New procedure } & M10 & 0 & 0 & 2 & 2 & 1 \\
\hline & M12 & 0 & 0 & 2 & 2 & 1 \\
\hline & M14 & 0 & 0 & 2 & 2 & 1 \\
\hline & M 15 & 0 & 0 & 2 & 2 & 1 \\
\hline & M 16 & 0 & 0 & 2 & 2 & 1 \\
\hline & M 20 & 0 & 0 & 2 & 2 & 1 \\
\hline & M 30 & 1 & 3 & 0 & 0 & 1 \\
\hline & M 40 & 1 & 1 & 0 & 2 & 1 \\
\hline & M 55 & 1 & 0 & 1 & 2 & 1 \\
\hline & M 60 & 0 & 1 & 3 & 0 & 1 \\
\hline & M 70 & 1 & 1 & 1 & 1 & 1 \\
\hline & Required capacity (min) & 34,000 & 48,000 & 47,800 & 47,800 & 44,400 \\
\hline & Orders $(\#)$ & & & & & \\
\hline \multirow[t]{12}{*}{ Traditional MRP } & M10 & 2 & 2 & 1 & 0 & 0 \\
\hline & M12 & 2 & 2 & 1 & 0 & 0 \\
\hline & M14 & 2 & 2 & 1 & 0 & 0 \\
\hline & M 15 & 2 & 2 & 1 & 0 & 0 \\
\hline & M 16 & 2 & 2 & 1 & 0 & 0 \\
\hline & M 20 & 2 & 2 & 1 & 0 & 0 \\
\hline & M 30 & 2 & 2 & 1 & 0 & 0 \\
\hline & M 40 & 2 & 2 & 1 & 0 & 0 \\
\hline & M 55 & 2 & 2 & 1 & 0 & 0 \\
\hline & M 60 & 2 & 2 & 1 & 0 & 0 \\
\hline & M 70 & 2 & 2 & 1 & 0 & 0 \\
\hline & Required capacity (min) & 88,800 & 88,800 & 44,400 & 0 & 0 \\
\hline
\end{tabular}




\section{Conclusions}

This paper introduced a capacity-oriented MRP procedure - based on a combination of the traditional infinite-capacity MRP procedure and a MILP-based approach - to help practitioners plan their production systems, by overcoming the requirement for lead times pre-determined a priori outside the MRP procedure.

Within the new model, the traditional MRP procedure allows calculating both the net requirements of all the finished products and semi-finished products and the orders of purchased items, for all the time buckets of the horizon, while the MILP model allows calculating the orders of all the finished and semi-finished products in each time bucket of the planning horizon. MILP solution is oriented (i) at complying with the production capacity of each resource, (ii) at minimising the cost of holding stock, and (iii) at covering net requirements and wastes.

Then, the proposed model has been applied to real-life company manufacturing manual valve actuators. Here, Table 10 shows the orders of broached quadrants given both by the new proposed model and by the traditional MRP procedure (where a 1-week lead time has been used for all the items of the BOM) and the corresponding required capacity (in minutes) of the broach.

Table 10 points out that the plan provided by the traditional MRP procedure does not comply with the broach capacity, whereas the one provided by the proposed model does. Besides, the lead time required by the traditional MRP procedure causes higher stock and, in this case, prevents the production system from exploiting the available capacity of the broach over the planning horizon. Since the first and the second week are both overloaded, the sole option to cope with the plan given by the traditional MRP procedure lies in outsourcing orders of broached quadrants for 40,800 minutes both in week 1 and in week 2 . In the end, due to the outsourcing costs and the higher costs of holding stock, the plan provided by the traditional MRP procedure is more expensive than the one given by the proposed model.

In addition, the new proposed model not only brings improvements in comparison to the traditional MRP procedure but also in comparison to the finite capacity MRP literature. With reference to the approaches presented in Table 1, the proposed model is the sole that does not require lead time as inputs, it considers capacity constraints along the calculation process and at all the levels of the BoM at once, and it has been applied to a real life (i.e. not-simplified) case (see also Table 2). Furthermore, again unlike the LP-based approaches found in literature (see Table 1) the new model significantly reduces the MILP problem complexity. In fact, the constraints considered in the model are only related the (limited) portion of the MRP table impacted by facilities capacity, which allows reducing the computational burden. Moreover, objective function considers only the fictitious cost and the quantity to be produced, thus avoiding the computation of the inventory level for each BoM level at the end of each period in the MILP model. The inventory level at the end of each period differs from availability since it should be calculated according to equation (12).

$$
\text { Final Inventory } \text { Level }_{f, i, t}=\left(\text { CumOrder }_{f, i, t}-\text { CumNReqWLot }_{f, i, t}\right) \cdot \operatorname{lot}_{f, i, t}
$$

For all the above mentioned reasons, the proposed model allows generating MRP plans in a very short time span (less than 3 minutes in the case presented here). Therefore, the proposed model proved helpful to production managers in getting feasible MRP plans for real-life industrial plants. To this purpose, the tool used to solve MILP problem triggers a

very promising future research path: the approach introduced here could be fruitfully up scaled, to make it suitable to more complex manufacturing environments than the one presented here as case study.

\section{Disclosure statement}

No potential conflict of interest was reported by the authors.

\section{References}

Agrawal, A., I. Minis, and R. Nagi. 2000. "Cycle Time Reduction by Improved MRP-based Production Planning." International Journal of Production Research 38 (18): 4823-4841.

Aouam, T., and R. Uzsoy. 2015. "Zero-order Production Planning Models with Stochastic Demand and Workload-dependent Lead times." International Journal of Production Research 53 (6): 1661-1679.

Billington, P. J., J. O. Mcclain, and L. J. Thomas. 1983. "Mathematical Programming Approaches to Capacity-constrained MRP Systems: Review, Formulation and Problem Reduction." Management Science 29 (10): 1126-1141.

Chase, R. B., N. J. Aquilano, and F. R. Jacobs. 1998. Production and Operations Management: Manufacturing and Services. New York: Irwin McGraw-Hill Ed.

Chen, K., and P. Ji. 2007. "A Mixed-integer Programming Model for Advanced Planning and Scheduling (APS)." European Journal of Operational Research 181 (1): 515-522. 
Cigolini, R., and T. Rossi. 2008. "Evaluating Supply Chain Integration: A Case Study Using Fuzzy Logic." Production Planning and Control 19 (3): 242-255.

Creazza, A., F. Dallari, and T. Rossi. 2012a. "An Integrated Model for Designing and Optimising an International Logistics Network." International Journal of Production Research 50 (11): 2925-2939.

Creazza, A., F. Dallari, and T. Rossi. 2012b. "Applying an Integrated Logistics Network Design and Optimisation Model: The Pirelli Tyre Case." International Journal of Production Research 50 (11): 3021-3038.

Dolgui, A., O. Ben Ammar, F. Hnaien, and M. A. Louly. 2013. "A State of the Art on Supply Planning and Inventory Control under Lead Time Uncertainty." Studies in Informatics and Control 22 (3): 255-268.

Enns, S. T. 2001. "MRP Performance Effects due to Lot Size and Planned Lead-time Settings." International Journal of Production Research 39 (3): 461-480.

Gansterer, M., C. Almeder, and R. F. Harti. 2014. "Simulation-based Optimization Methods for Setting Production Planning Parameters." International Journal of Production Economics 151: 206-213.

Godin, V., and C. Jones. 1969. The Interactive Shop Supervisor, Industrial Engineering, November, 16-22.

Goldratt, E. 1980. Optimized Production Timetable: A Revolutionary Program for Industry. In APICS 23rd Annual Conference Proceedings, Los Angeles.

Horiguchi, K., N. Raghavan, R. Uzsoy, and S. Venkateswaran. 2001. "Finite-capacity Production Planning Algorithms for a Semiconductor Wafer Fabrication Facility." International Journal of Production Research 39 (5): 825-842. doi:10.1080/ 00207540010010253.

Ioannou, G., and S. Dimitriou. 2012. "Lead Time Estimation in MRP/ERP for Make-to-order Manufacturing Systems." International Journal of Production Economics 139 (2): 551-563.

Jodlbauer, H., and S. Reitner. 2012. "Material and Capacity Requirements Planning with Dynamic Lead times." International Journal of Production Research 50 (16): 4477-4492. doi:10.1080/00207543.2011.603707.

Jonsson, P., and S. Mattsson. 2006. "A Longitudinal Study of Material Planning Applications in Manufacturing Companies.” International Journal of Operations \& Production Management 26: 971-995.

Kacar, N. B., and R. Uzsoy. 2014. "A Comparison of Multiple Linear Regression Approaches for Fitting Clearing Functions to Empirical Data." International Journal of Production Research 52 (11): 3164-3184. doi:10.1080/00207543.2013.864052.

Kanet, J., and M. Stößlein. 2010. "Integrating Production Planning and Control: Towards a Simple Model for Capacitated ERP." Production Planning and Control 21 (3): 286-300.

Lee, H.-G., N. Park, and J. Park. 2009. “A High Performance Finite Capacitated MRP Using a Computational Grid.” International Journal of Production Research 47 (8): 2109-2123.

Little, J. G. 1961. "A Proof for the Queuing Formula: L= $\lambda$ W." Operations Research 9 (3): 383-387.

Milne, R. J., C. T. Wang, C. K. Yen, and K. Fordyce. 2012. "Optimized Material Requirements Planning for Semiconductor Manufacturing.” Journal of the Operational Research Society 63 (11): 1566-1577. doi:10.1057/jors.2012.1.

Milne, R. J., S. Mahapatra, and C. T. Wang. 2015. "Optimizing Planned Lead times for Enhancing Performance of MRP Systems." International Journal of Production Economics 167: 220-231.

Miltenburg, J. 2001. "Computational Complexity of Algorithms for MRP and JIT Production Planning Problems in Enterprise Resource Planning Systems.” Production Planning and Control 12 (2): 198-209. doi:10.1080/09537280150501293.

Molinder, A., and J. Olhager. 1998. "The Effect of MRP Lot Sizing on Actual Cumulative Lead times in Multi-level Systems." Production Planning and Control 9 (3): 293-302.

Mula, J., R. Poler, and J. P. Garcia. 2006. "MRP with Flexible Constraints: A Fuzzy Mathematical Programming Approach.” Fuzzy Sets and Systems 157 (1): 74-97.

Nagendra, P. B., and S. K. Das. 2001. "Finite Capacity Scheduling Method for MRP with Lot Size Restrictions." International Journal of Production Research 39 (8): 1603-1623.

Orlicky, J. A. 1976. Materials Requirement Planning. New York: McGraw-Hill.

Ornek, M., and O. Cengiz. 2006. "Capacitated Lot Sizing with Alternative Routings and Overtime Decisions." International Journal of Production Research 44 (24): 5363-5389.

Öztürk, C., and A. M. Örnek. 2012. “A MIP Based Heuristic for Capacitated MRP Systems.” Computers and Industrial Engineering 63 (4): 926-942. doi:10.1016/j.cie.2012.06.005.

Pandey, P. C., P. Yenradee, and S. Archriyapruek. 2000. “A Finite Capacity Material Requirements Planning System.” Production Planning and Control 11 (2): 113-121.

Reiter, S. 1966. A System for Managing Job Shop Production. Journal of Business 3: 371-393.

Rossi, T., and M. Pero. 2011. "A Simulation-based Finite Capacity MRP Procedure Not Depending on Lead-time Estimation." International Journal of Operational Research 11 (3): 237-261.

Segerstedt, A. 1996. "Formulas of MRP." International Journal of Production Economics 46-47: 127-136. doi:10.1016/0925-5273 (95)00163-8.

Sun, L., S. S. Heragu, L. Chen, and M. L. Spearman. 2012. "Comparing Dynamic Risk-based Scheduling Methods with MRP via Simulation.” International Journal of Production Research 50 (4): 921-937. doi:10.1080/00207543.2011.556152.

Taal, M., and J. C. Wortmann. 1997. "Integrating MRP and Finite Capacity Planning." Production Planning and Control 8 (3): 245-254. 
Weintraub, A. J., A. Zozom, Jr., T. J. Hodgson, and D. Cormier 1997. A Simulation Based Finite Capacity Scheduling System. In Proceedings of the 1997 Winter Simulation Conference, Atlanta, 838-844.

Wight, O. W. 1995. The Executive's Guide to Successful MRP II. Vol. 6. New York: Wiley.

Wuttipornpun, T., and P. Yenradee. 2004. "Development of Finite Capacity Material Requirement Planning System for Assembly Operations." Production Planning and Control 15 (5): 534-549. 